\title{
De infravivienda a recurso turístico, las casas-cuevas de Baza y Guadix
}

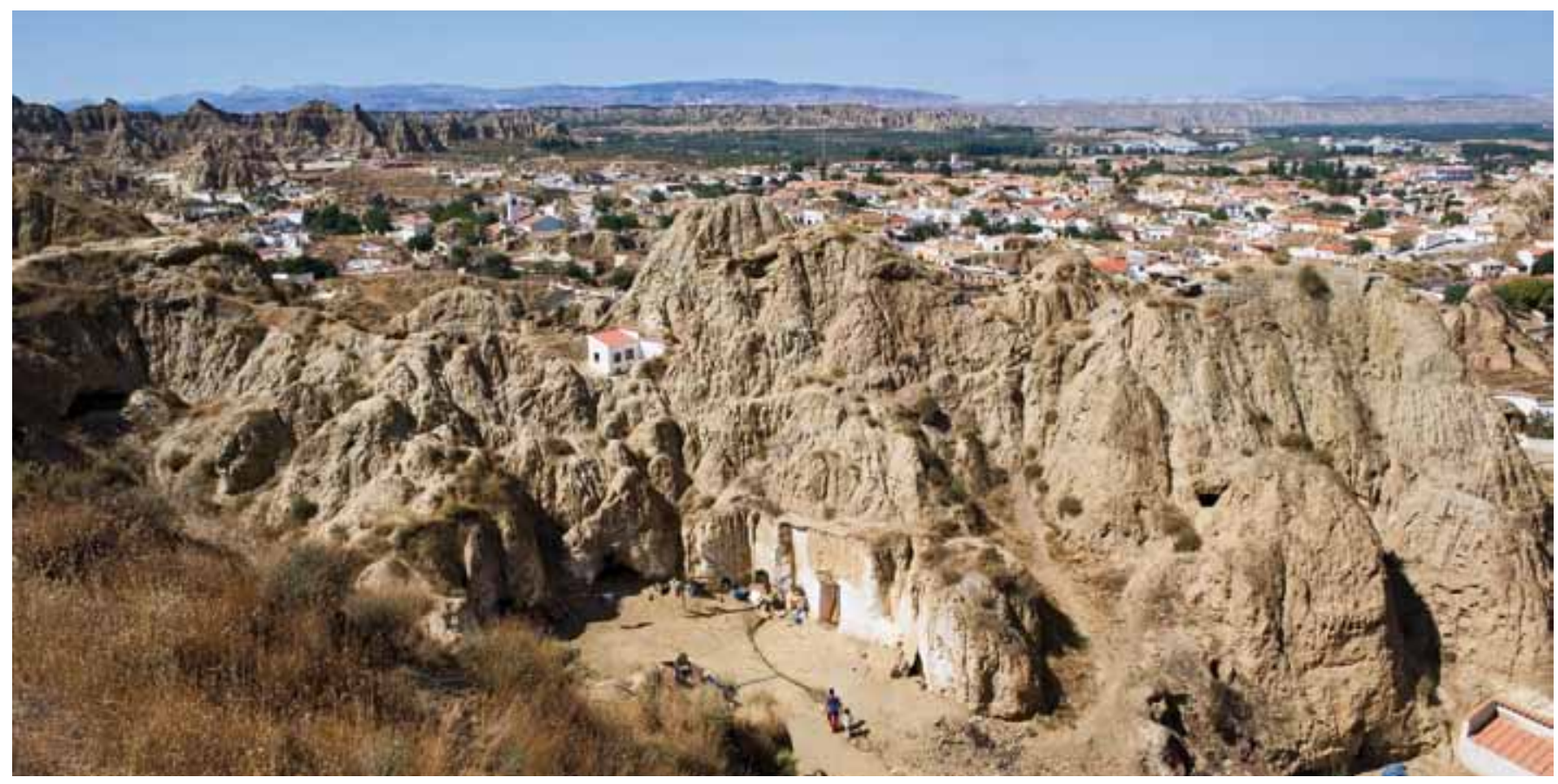

En sus orígenes la casa-cueva se ubicaba en zonas periféricas muy escarpadas. Aquí, vista general de casas-cuevas en Guadix.

Foto: Fondo Gráfico IAPH Uuan Carlos Cazalla, para todas las imágenes de Guadix).

"Hacer de la necesidad virtud" es un refrán que los habitantes de las hoyas de Baza y Guadix parecen haberse tomado muy en serio. En un medio ambiente que impone serias limitaciones y con un climatología que alcanza valores extremos tanto en verano como en invierno, han logrado adaptarse al entorno (y adaptar dicho entorno) sacando el máximo provecho de los recursos disponibles.

Un claro ejemplo de esta adaptación lo tenemos en la excavación de cuevas y casas-cuevas en casi todos los municipios. Estas viviendas aprovechan los desniveles naturales del terreno, penetrando en la tierra en un plano horizontal y, por lo general las habitaciones no profundizan mucho con respecto a la fachada a fin de mantener la necesaria ventilación. En el caso de las casas-cuevas, a las dependencias excavadas las antecede algún tipo de construcción exterior que protege la ladera excavada de las inclemencias del tiempo.

Si bien existen datos que vinculan algunos de estos espacios excavados con el periodo del reino nazari de Granada y con épocas inmediatamente posteriores,

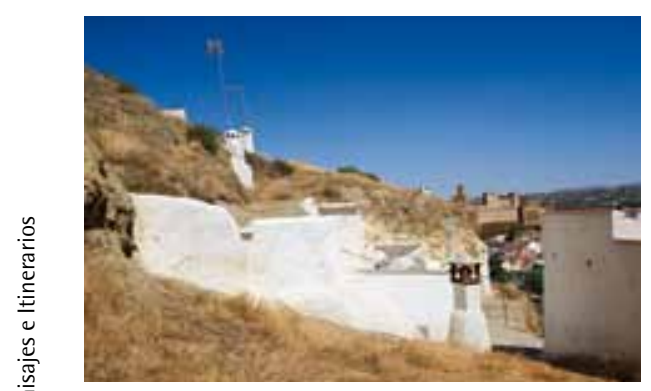

Casa-cueva de Guadix. Vista lateral no será hasta mediados del siglo XVIII cuando comiencen a proliferar este tipo de moradas. De hecho, los mayores incrementos en el número de cuevas son relativamente recientes, concretamente de finales del siglo XIX y de mediados del siglo XX, épocas de gran crecimiento poblacional y que supusieron una gran demanda de vivienda nueva.

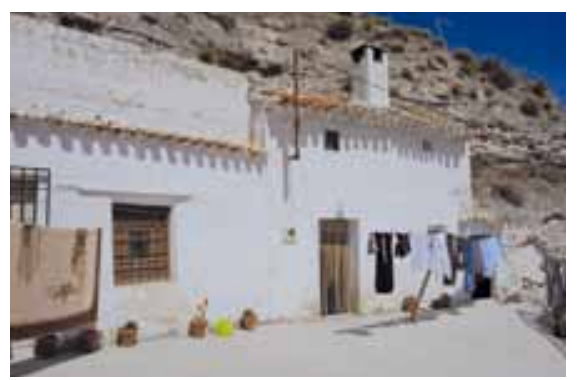

Casa-cueva en Galera. Foto: Miguel Ángel Mejías del Río (de todas las imágenes de Galera)

Así pues, la cueva se configura en su origen como un hábitat económico, autoconstruido en su mayor parte, y que necesita de pocos recursos para ofrecer unas condiciones óptimas de habitabilidad. Por ejemplo, este tipo de viviendas tienen la capacidad de autorregular su temperatura, manteniéndola a lo largo de todo el año en torno a los $20^{\circ} \mathrm{C}$. El principal sector de la población que las ha habitado durante un largo periodo histórico estaba constituido por jornaleros sin tierras y pequeños propietarios, aunque en algunas poblaciones, como Galera y Orce, también los medianos propietarios vivian en casas-cuevas.

Teniendo en cuenta los orígenes a los que se vincula la excavación de cuevas, se trata de una vivienda autoconstruida por inmigrantes jornaleros normalmente en zonas periféricas o escasamente urbanizadas como la parte alta de los montes o laderas muy escarpadas (y con las consecuentes dificultades de acceso). No es de extrañar que durante mucho tiempo hayan sido consideradas infraviviendas. Esta situación se agudiza a partir de los años 70 y 80 del s. XX cuando las casas empiezan a dotarse de conexión eléctrica y de agua corriente, pero no asi las cuevas, muchas de las cuales se enclavaban en lugares donde el suministro de agua conllevaba grandes problemas.

A pesar de ello, lejos de ser una construcción minoritaria o en vias de desaparecer, la densidad de cuevas sobre el total del entramado urbano en muchas localidades alcanzó porcentajes muy elevados y actualmente es todavía considerablemente alta. En casos como los de Gorafe, Benalúa, Castillejar, Benamaurel o Galera, podemos encontrar aún hoy a más del 50\% de la población residiendo en viviendas subterráneas. Sin embargo, es cierto que desde los años 70 el total de cuevas y casas-cuevas habitadas ha sufrido un descenso global generalizado. La principal razón de esta disminución la hemos de buscar en las sucesivas oleadas emigratorias que tuvieron lugar durante el último tercio del siglo $X X$, unidas a la depreciación del precio de la vivienda en estas poblaciones, lo que permitió a los vecinos restantes adquirir viviendas de construcción, más apreciadas.

De modo general podemos observar cómo para finales de los años 80 la población se habia reducido en la mayoria de las poblaciones, desplazándose además los vecinos remanentes a viviendas situadas en la parte central de las mismas, en muchos casos se 
trataba de casas o casas-cuevas reformadas, abandonándose así barrios de cuevas casi por completo 0 destinándose las antiguas viviendas a lugar de guarda para el ganado. La mayoría de las cuevas desalojadas se encontraban en los alrededores de los pueblos o en las zonas más elevadas, por ser las menos apreciadas, lo cual tendrá consecuencias inesperadas décadas más tarde.

Las reformas llevadas a cabo por los vecinos que permanecieron en las cuevas tendían a lograr una mayor comodidad y salubridad en la vivienda, con la adición de cuarto de baño y cocina a expensas de la placeta exterior y proyectando una pequeña construcción, por lo que pasariamos ya a hablar de una casa-cueva, y a adaptarse al "estándar" de vivienda, esto es, eliminar las superficies irregulares, cambiar las cortinas interiores por puertas, sustitución de las antiguas solerias por otras nuevas, etc. De este modo se produce una primera dualidad entre cuevas abandonadas o destinadas a usos agropecuarios en la periferia, y casas-cuevas reformadas e integradas con el paisaje edificado en los barrios más céntricos.

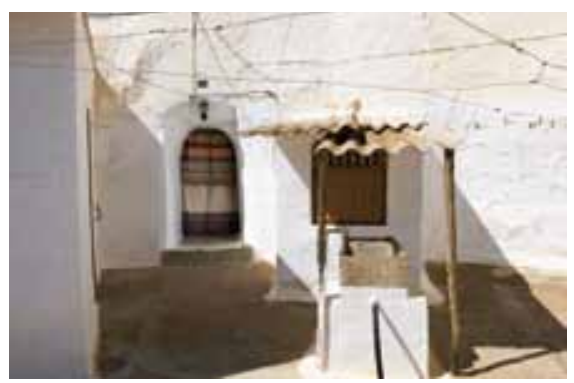

Guadix. Detalle de la entrada de una casa-cueva

En general, la situación que se presentaba a finales del siglo pasado no dejaba de ser un reflejo de lo que ocurría en muchos otros pueblos españoles: ante la ausencia de oportunidades laborales fuera del sector agropecuario, la población se desplazaba a zonas

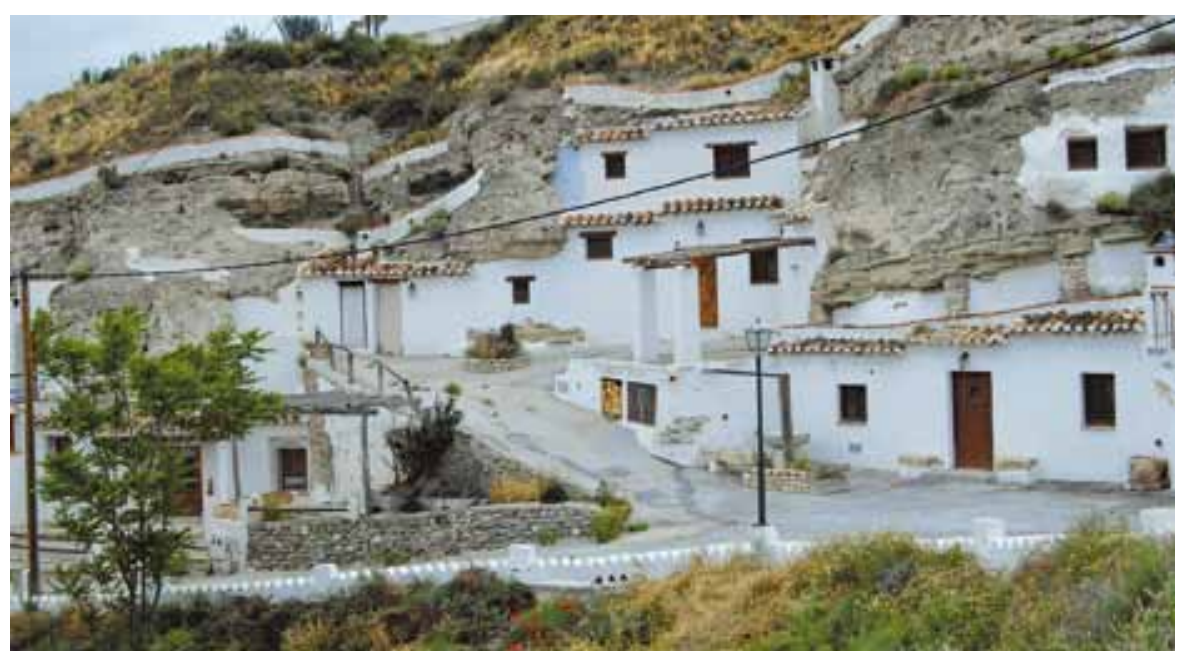

Las casas-cuevas necesitan de pocos recursos para ofrecer unas condiciones óptimas de habitabilidad. En la imagen casas-cuevas de Galera han protagonizado los promotores inmobiliarios en

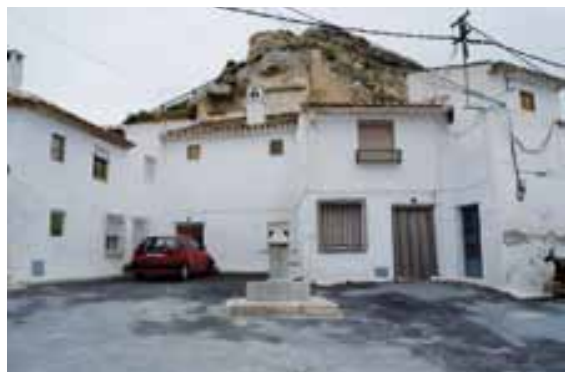

Casa-cueva en Galera. Vista frontal

costeras o a grandes ciudades. Pero ya a mediados de los años 90 se podía apreciar un cambio significativo en localidades como Galera y Guadix. Vecinos de la zona adquirian cuevas y casas-cuevas abandonadas y tras rehabilitarlas la abrian como hoteles rurales o las vendian como segunda residencia.

Este fenómeno ha dado lugar a uno de los procesos más interesantes en lo referido a la arquitectura vernácula: la recuperación de viviendas tradicionales en el marco de un discurso patrimonialista. Huelga decir que no se trata de un hecho exclusivo de esta zona, sino que se extiende por numerosas zonas rurales de toda la Península Ibérica, no obstante, ciertas particularidades que podemos encontrar en las hoyas de Baza y Guadix lo hacen digno de estudio.

El retorno de algunos vecinos emigrados no ha supuesto un cambio significativo, no asi la demanda de una vivienda de vacaciones por parte de otros y sus descendientes, los cuales han optado en muchos casos por reformar la cueva de la familia, adaptando los espacios que otrora se dedicaron al almacenaje, a dormitorios, y dotando las residencias de las comodidades de las que carecieron sus ascendientes.

Ahora bien, la transformación más significativa la consonancia con grupos de inmigrantes de Euro- pa occidental, en su mayoría ciudadanos británicos jubilados. Se trataría de una particular simbiosis en la que unos demandan una vivienda de acuerdo a ciertos estereotipos culturales, y otros "rediseñan" las cuevas conforme a los gustos que les suponen a los potenciales compradores.

De este modo podriamos, de hecho, hablar de la creación de una pequeña explosión inmobiliaria a la vista del incremento en el número de cuevas y casascuevas rehabilitadas. Dichas rehabilitaciones se han realizado respondiendo a discursos ruralizantes y neopatrimonialistas que poco o nada tenían que ver con la tradición constructiva precedente. Además se produce una inversión total en cuanto a la valoración pecuniaria de las cuevas, ya que aumenta el valor de las viviendas excavadas emplazadas en altura o alejadas del centro de los pueblos, pues gozan de mejores vistas, más espacio, posibilidad de un acceso rodado independiente, etc.

Es asi que podemos afirmar que se ha generado un nuevo dualismo en cuanto a las cuevas y casas-cuevas. Por un lado, aquellas ocupadas por pobladores autóctonos, totalmente mimetizadas con el entorno y cuyo interior tiende a asemejarse al de una vivienda de construcción; por otro lado, las destinadas a turistas o inmigrantes europeos, con un exterior que recuerda a postales de aires romanticistas e interiores cargados de objetos de la vida rural totalmente descontextualizados.

En resumen, en los últimos quince años se ha producido una inversión casi total en cuanto a la consideración social de las cuevas y casas-cuevas gracias a los nuevos usos asociados a este tipo de construcciones, que han supuesto su revaloración como recurso económico, principalmente turístico, orientado a un nuevo tipo de residentes que difieren radicalmente de los jornaleros que en su día las excavaron. Las consecuencias que este cambio de apreciación tendrá en el futuro no lo podemos adelantar, pero será necesario conjugar de algún modo las necesidades de los nuevos pobladores con la tradición y el valor identitario que poseen las cuevas.

\section{José Miguel Mejias del Río}

Antropólogo 